\title{
Towards a personalized task selection model with shared instructional control
}

Citation for published version (APA):

Corbalan Perez, G., Kester, L., \& Van Merriënboer, J. (2006). Towards a personalized task selection model with shared instructional control. Instructional Science, 34(5), 399-422. https://doi.org/10.1007/s11251-005-5774-2

DOI:

$10.1007 / \mathrm{s} 11251-005-5774-2$

Document status and date:

Published: 01/09/2006

Document Version:

Peer reviewed version

Please check the document version of this publication:

- A submitted manuscript is the version of the article upon submission and before peer-review. There can be important differences between the submitted version and the official published version of record. People interested in the research are advised to contact the author for the final version of the publication, or visit the DOI to the publisher's website.

- The final author version and the galley proof are versions of the publication after peer review.

- The final published version features the final layout of the paper including the volume, issue and page numbers.

Link to publication

\section{General rights}

Copyright and moral rights for the publications made accessible in the public portal are retained by the authors and/or other copyright owners and it is a condition of accessing publications that users recognise and abide by the legal requirements associated with these rights.

- Users may download and print one copy of any publication from the public portal for the purpose of private study or research.

- You may not further distribute the material or use it for any profit-making activity or commercial gain

- You may freely distribute the URL identifying the publication in the public portal.

If the publication is distributed under the terms of Article 25fa of the Dutch Copyright Act, indicated by the "Taverne" license above, please follow below link for the End User Agreement:

https://www.ou.nl/taverne-agreement

Take down policy

If you believe that this document breaches copyright please contact us at:

pure-support@ou.nl

providing details and we will investigate your claim.

Downloaded from https://research.ou.nl/ on date: 26 Apr. 2023 
1Running head: SHARED CONTROL OVER TASK SELECTION

This is a pre-print of the article that was published as

Corbalan, G., Kester, L., \& Van Merriënboer, J .J. G. (2006). Towards a personalized task selection model with shared instructional control. Instructional Science, 34 , 399-422.

http://www.springerlink.com/content/k476v5x576125823/

owards a Personalized Task Selection Model with Shared Instructional Control

\author{
Gemma Corbalan* \\ Liesbeth Kester
}

Jeroen J. G. van Merriënboer

Open University of the Netherlands, Educational Technology Expertise Center

P.O. Box 2960, 6401 DL Heerlen, The Netherlands.

Telephone: +31 45 5762909, Fax: +31 455762802

Email: gemma.corbalan@ou.nl

This research project is funded by the Netherlands Organization for Scientific Research (NWO, The Hague, project no. 411-02-107-V). 


\begin{abstract}
Modern education emphasizes the need to flexibly personalize learning tasks to individual learners. This article discusses a personalized task-selection model with shared instructional control based on two current tendencies for the dynamic sequencing of learning tasks: (1) personalization by an instructional agent which makes sequencing decisions on the basis of learner's expertise, and (2) personalization by the learner who is given control over -finaltask selection. The model combines both trends in a model with shared instructional control. From all available learning tasks, an instructional agent selects a subset of tasks based on the learner's performance scores and invested mental effort (i.e., system-control). Subsequently, this subset is presented to the learner who makes the final decision (i.e., learner control). A computer-assisted instructional program has been developed to put the model into practice and preliminary results are discussed. The model can be used to increase the efficiency and effectiveness of instruction and to make it more appealing by providing the learner an optimal level of control over task selection.
\end{abstract}

Key words: Cognitive load, complex learning, dynamic task selection, electronic learning environment, learner control, personalized instruction. 


\section{Introduction}

Rapid technological developments in modern society increase students' need to acquire complex cognitive skills and to transfer those skills from formal educational settings to work situations (Reigeluth, 1999; van Merriënboer \& Kirschner, 2001). There is a tendency in the field of instructional design to focus on authentic learning tasks based on real-life situations to help learners develop transferable skills. But especially for novice learners, the acquisition of complex skills by performing authentic learning tasks is heavily constrained by the limited processing capacity of working memory because it easily causes cognitive overload.

According to cognitive load theory (Sweller, 1988; Sweller, van Merriënboer, \& Paas, 1998; van Merriënboer \& Sweller, 2005), cognitive load is a construct representing the load that performing a particular task imposes on the human cognitive system. Learning is encouraged if the cognitive system is not overloaded and if available cognitive resources are actually allocated to learning processes rather than extraneous processes that do not directly contribute to learning.

In order to enable the use of authentic tasks in education, and simultaneously prevent learners from being overwhelmed by them, there is a need to personalize the nature and sequence of learning tasks for each individual learner. Personalization of learning materials to individual learners is believed to facilitate learning, because (a) the level of difficulty and available support of each task prevents cognitive overload, and (b) other task features are varied in such a way that learning is promoted. This article describes a model of personalized task selection which enables the development of personalized education. The model combines two approaches to personalization in order to cope with increasingly complex learning situations: System-controlled instruction, in which an instructional agent (e.g., computer, teacher) makes decisions on learning tasks, and learner-controlled instruction, in which the learner him or herself makes such decisions. 
First, according to models of system-controlled instruction, learning is influenced by both characteristics of the learner, such as expertise, abilities, and attitudes (Zimmerman, 2002), and characteristics of the tasks that are presented in the learning environment, such as task complexity, amount of learner support, and other task features (Lawless \& Brown, 1997). The use of electronic learning environments allows for personalization by changing the instruction (i.e., learning tasks) in response to input from the learner. Several studies indicate that such personalization leads to a more efficient training program and higher transfer test performance than the use of a fixed sequence of ready-made learning tasks (e.g., Camp, Paas, Rikers, \& van Merriënboer, 2001; Kalyuga \& Sweller, 2005; Salden, Paas, Broers, \& van Merriënboer, 2004; van Merriënboer, Schuurman, de Croock, \& Paas, 2002).

Second, according to models of learner-controlled instruction, complex learning should not only aim at developing complex skills but also at promoting self-regulated learners who are able to effectively select their own learning tasks. Pure system-controlled instruction cannot enhance the acquisition of self-regulation skills because an instructional agent rather than the learner makes the selection. Giving learners - some - control over particular aspects of their learning environment creates the necessary preconditions for practicing selfregulation skills and is a first step towards teaching those skills (Kinzie, 1990). In addition, it is expected to make learning more appealing with beneficial effects on learner motivation, which in turn may increase learning outcomes (Wolters, 2003; Zimmerman, 2002). Giving learners control over task selection assumes that learners are able to select the most suitable learning task according to their current state of knowledge, interests, and preferences (van Merriënboer et al., 2002). Novices in a particular learning domain who are provided with learner control, however, may not be able to pick up essential information for learning so that there is a decrease in learning and learning goals are not reached (Merrill, 2002). More 
experienced learners have the necessary knowledge to make the right selections, and giving them learner control prevents that they receive information they already know.

Concluding, there should be a gradual transition from system-control to learnercontrol if learners acquire more expertise. But, even experienced learners may not profit from full learner control if they are overwhelmed by the amount of choice, for instance, if they have to select from hundreds of tasks (Schwartz, 2004). Thus, for a novice learner it is best to select one learning task from a small set of available tasks; for a more experienced learner it is best to select one learning task from a larger set of tasks, but even a highly experienced learner should not select one learning task from a very large set of tasks. The personalized task-selection model with shared instructional control presented in this article combines the advantages of both system-controlled and learner-controlled instruction. When a learner works on learning tasks, an instructional agent continuously assesses performance and invested mental effort to select an optimal subset of following learning tasks. This subset is then presented to the learner who makes the final selection. Thus, the instructional agent and the learner share control over the whole process of learning task selection. Shared control is expected to be more effective (i.e., higher learner performance) and more efficient (i.e., higher performance combined with lower mental effort invested and/or less instructional time) than both complete system and learner control. In addition, it is believed to be more appealing and to promote the development of self-regulation skills.

The structure of this paper is as follows. First, a description of the model and its main components is given. Second, the model is translated into practice and a specific learning environment which is developed on the basis of the model is described. Finally, the results obtained in a pilot study that examined the effects of the learning environment are described and the implications of the results are discussed.

\section{The Model}


The personalized task-selection model with shared instructional control aims at providing each individual learner, after finishing one or more learning tasks, the best next task given his or her level of expertise, thus yielding a personalized sequence of learning tasks in an environment for complex learning.

Figure 1 Figure 1 gives a diagram of the model including three components: (a) characteristics (component C), (b) personalization (component P), and (c) learning-task database (component L).

Component $\mathrm{C}$ includes task characteristics and learner characteristics, which are documented in a learner portfolio. Task characteristics include the level of complexity (i.e., from simple to complex, or from easy to difficult), embedded learner support (i.e., from full support to no support), and other task features (e.g., the context in which the task is performed, characteristics of task input and output, display and presentation mode, et cetera). The learner portfolio contains, for instance, information about the learner in terms of task performance and invested mental effort on already completed learning tasks, combined in a measure of expertise.

Component $\mathrm{P}$ refers to the personalization mechanism. It combines two apparent opposite tendencies of personalization: System-controlled instruction and learner-controlled instruction. System-controlled instruction includes task-selection rules used by an instructional agent to base decisions on. Learner-controlled instruction lets the learner select the learning tasks from a smaller or larger subset of—-preselected—-tasks. Both forms complement each other in such a manner that when the system has a relatively large control over task selection, the learner receives a relatively small amount of control, and vice versa. In that way, control is shared by the system and the learner. The relative amount of system and learner control over task selection varies based on the contents of the learner portfolio. 
Finally, Component L includes the learning-task database with tasks with diverse levels of complexity, embedded support, and other task features. The instructional agent preselects a subset of learning tasks from this database and presents only this subset to the learner, who should make the final selection. Theoretically, the size of this subset may range from 1 (i.e., no learner control) to all tasks in the database (i.e., full learner control).

\section{Component C: Characteristics}

Component $\mathrm{C}$ refers to learning task characteristics and the learner portfolio. If the characteristics of the task presented to an individual learner are not appropriate this may either hamper learning because of cognitive overload, if the task is too difficult or does not include enough support, or hamper learning because the task features do not stimulate the learner to construct new knowledge. The learner portfolio should contain the information that helps to select the best task(s) for learning. Relevant task characteristics and the learner portfolio are discussed in the next subsections.

Learning task characteristics. The four-component instructional design model (4C/IDmodel; van Merriënboer, 1997; van Merriënboer, Clark, \& de Croock, 2002) provides guidelines that consider the limitations of working memory for the design of educational programs, or integrated curricula, to teach complex cognitive skills. In an integrated curriculum, learning tasks are ordered in an easy-to-difficult sequence, learner support decreases from high to no support, and learning tasks vary from each other on external characteristics that also differ in the real world (e.g., context, display and presentation mode, input for the task, et cetera). Our personalized task-selection model with shared instructional control takes the 4C/ID-model as a starting point and distinguishes the same three aspects of learning tasks for personalization: (a) level of complexity, (b) embedded learner support, and (c) other task features. Learner support decreases and task complexity increases as learner's level of expertise increases. Moreover, varying other task features increases the variability of 
practice, which promotes learners to construct new knowledge through abstraction and generalization (van Merriënboer, 1997).

First, with regard to the level of complexity it is argued that, due to limited processing capacity, providing very difficult learning tasks right from the start of a curriculum may have negative influences on learning, performance, and motivation (van Merriënboer, Kirschner, \& Kester, 2003). In terms of cognitive load theory the difficulty of a task yields intrinsic cognitive load, which is a direct result of the complex nature of the learning material. That is, intrinsic cognitive load is higher when the elements of the learning material are highly interconnected (i.e., high element interactivity) and lower when they are less interconnected (low element interactivity; for a review, see Sweller, 1994). A personalized instructional design should provide each learner with tasks that are neither too difficult nor too easy. By gradually increasing the difficulty of tasks in such a way that the individual learner's growing expertise is taken into account, the intrinsic cognitive load yielded by these tasks is properly managed.

Second, providing learners with tasks with an appropriate amount of embedded support is essential for learning because this prevents cognitive overload as well. This embedded support is related to the sequence of operators (i.e., the solution steps) necessary to reach the goal state. Different types of embedded support take different aspects of the problem solving process into account. Product support provides the learners with solution steps; process support presents the rationale behind the problem-solving process itself (van Merriënboer, 1997).

Worked-out examples are learning tasks that provide maximum product-oriented support. They confront the learners not only with a description of a given state (i.e., problem state) and the criterion for an acceptable goal state or solution, but also with a description of the solution steps necessary to reach the solution. The learners are asked to carefully study the 
solution or 'best example'. Worked-out examples prevent extraneous cognitive load, that is, load irrelevant for learning because learners do not have to bother about the tentative application of mental operations but can focus all their attention on learning the relevant solution steps. Completion problems provide learners with a partial rather than a complete solution. Like worked-out examples, they help learners focus on the problem state and relevant solution steps. But in addition, learners have to carefully study the partial solution because otherwise they will not be able to find the remaining solution steps. This directs learners' attention to processes relevant for learning, hereby enhancing so-called germane cognitive load (i.e., load relevant for learning) and facilitating problem solving and transfer performance (Renkl \& Atkinson, 2003; van Merriënboer et al., 2002). Conventional tasks, finally, provide learners with a given state and a criterion for an acceptable only. No solution is provided. For experienced learners, conventional tasks enhance the generation of creative solutions because the tasks are authentic and the learners already possess the knowledge that is necessary to approach the task. But novice learners lack relevant knowledge and use cognitively demanding strategies to reach the solution, increasing extraneous cognitive load and hampering learning. Thus, a smooth transition from worked-out examples, through completion tasks, to conventional tasks takes learners growth in expertise into account.

At this respect, the 'expertise reversal effect' (Kalyuga, Ayres, Chandler, \& Sweller, 2003) states that successful instructional techniques for novice learners (e.g., presenting tasks with high embedded support) often lose their value, or even produce opposite effects, when used with more experienced learners. For instance, presenting a diagram with integrated textual explanations may be an effective technique for novice learners, who need the explanations to understand the diagram, but an ineffective technique for experienced learners, who already possess the knowledge necessary to understand the diagram. When they are nonetheless forced to process the textual information that is redundant with their current 
knowledge, this hinders learning because they must unnecessarily invest cognitive resources (i.e., extraneous cognitive load) to find out that the information is redundant.

Process-oriented support provides learners with heuristics for problem solving that may help them to reach an acceptable solution. Three types of process-oriented support are modeling examples, process worksheets, and performance constraints (Van Merriënboer, 1997). Modeling examples present the learner with an expert or professional who is demonstrating the problem solving process and explaining the reasoning behind it, thus verbalizing why s/he is doing what $\mathrm{s} / \mathrm{he}$ is doing. Process worksheets, in a paper-based format or as an on-line tool, provide a description of helpful phases and rules-of-thumb to guide learners through the problem-solving process. Finally, performance constraints force learners to use expert's approaches to problem solving while they are performing the learning tasks.

Third, learning tasks should differ from each other on task features that also differ in the real world. Examples are the context or setting in which the task is performed, the values of the given state of a problem (e.g., the same formula with different values), the way the task is displayed, the interface that is used, and the mode of presentation of the task (e.g., video, audio, graphics, or text). By designing tasks with varying task features, variability of practice is increased. Variability of practice enhances germane cognitive load because it promotes learners to develop generalized and abstract knowledge: It increases the probability that similar features are identified and that relevant features are distinguished from irrelevant ones (van Merriënboer, 1997). Moreover, variability of practice is an effective strategy for gaining and keeping a learner's attention (Paas, Tuovinen, van Merriënboer, \& Darabi, in press). If learners can choose between tasks with different features, they may select a task according to their interests which positively affects learning.

To conclude, the personalized task-selection model with shared instructional control aims at personalizing the level of task difficulty, the level of embedded learner support, and 
the other task features. Personalization takes place in such a way that intrinsic load is optimized, extraneous load decreased, and germane load increased - all within the limits of totally available cognitive resources.

Learner portfolio. Besides learning task characteristics, component $\mathrm{C}$ also takes learner characteristics, kept in a learner portfolio, into account. Individual differences between learners strongly influence how instruction must be designed in order to be most effective (Shute \& Towle, 2003). According to our personalized task-selection model, the characteristics of each learner are represented in the portfolio at each specific moment in time, and so provide the basis for the dynamic selection of one or more appropriate learning tasks. Three aspects of the learner taken into account for task-selection purposes are: (a) task performance, (b) invested mental effort, and (c) level of expertise.

The first aspect, performance, is commonly used as input for dynamic task selection and can be defined as the effectiveness in accomplishing a particular task (Camp et al., 2001). Continuous assessment is needed for the dynamic personalization of learning tasks. Assessment can either be made by a human or an electronic tutor, a peer (peer-assessment), or even the learner himself (self-assessment). The Protocol Portfolio Scoring (PPS; Straetmans, Sluijsmans, Bolhuis, \& van Merriënboer, 2003) argues that to gather reliable and valid information about a learner's performance, complex behaviours must be assessed on multiple aspects, which require different embedded assessment methods. According to the PPS, performance on tasks with support (e.g., worked-out examples, completion tasks) is mainly used to decide on the appropriate level of support and the desirable task features of subsequent tasks. Performance on conventional tasks without support is mainly used to decide whether the learner is ready to advance to a higher difficulty level or whether the learner has completed the whole educational program. 
Three often used measures of performance are time-on-task, process quality, and product quality. Assessment of time-on-task is an important measure in learning tasks where speed plays a crucial role for acceptable performance (e.g., physical activities, driving a car, controlling air traffic, et cetera). Time-on-task may indicate how easy or difficult a learning task was for a particular learner because it typically increases with complexity. Accordingly, if time on task is very high for a learner it may also indicate high cognitive load or even overload. Thus, a learner who needs a considerable investment of time to perform a specific learning task should not be given the same subsequent learning task as another learner who performed the same task in considerably less time.

The quality of the process indicates learners' understanding of the principles underlying their responses or solutions. Process data include verbal protocols, video and audio tapes, and retrospective reports. Observation instruments provide information on the accuracy of learners' actions, errors, misconceptions, and so forth. The quality of the available knowledge can also be measured by a variety of traditional assessment tools, such as checklists, multiple-choice questions, open questions and so forth.

The quality of the finished product indicates if the learner already masters required knowledge and skills. Detailed standards of performance in terms of what learners should be able to do, according to particular values and exhibiting particular attitudes, help to assess the quality of the product. Standards must be observable and measurable. For instance, one standard of performance in a course on dieting could be: "learners have to be able to find a balance between the energy intake and the energy expenditure of a person who is on a diet".

The second aspect, invested mental effort, refers to "...the cognitive capacity that is actually allocated by the learner to accommodate the demands imposed by the task" (Paas, Tuovinen, Tabbers, \& van Gerven, 2003, p. 64). Paas et al., (2003) describe two classes of methods for measuring mental effort: Subjective techniques (e.g., rating scales, self reports) 
and objective techniques (i.e., dual-task reaction times, heart-rate variability, pupillary dilation). Cognitive load is commonly measured by the mental effort invested in task performance. According to Paas et al., (2003) a meaningful interpretation of cognitive load measures can only be given in the context of its associated performance and vice versa.

This leads to the third aspect, learner expertise, which refers in our model to the combination of performance and mental effort. The 4C/ID-model states that performance measures alone are not a sufficient basis for task selection and should be enhanced by considering the investment of mental effort to attain this performance. Thus, if two learners reach the same performance but one learner invests a lot of mental effort and the other does not, the first learner is best presented with an easier new learning task than the second learner.

Recent methods for the assessment of expertise focus on the combination of measures of performance and cognitive load (van Merriënboer \& Sweller, 2005). Dynamic taskselection approaches require the just-in-time gathering of learner's data. Thus, the level of expertise is continuously assessed, updated in the portfolio after each learning task, and used to determine the optimum level of learner support, task complexity, and other task features of the next learning task. It takes the expertise reversal effect into account by selecting only the task(s) adapted to the learner's current expertise.

\section{Component P: Personalization}

The model combines system-controlled and learner-controlled approaches to reach a situation in which the instructional agent and the learner share responsibility over task selection. To which extent one approach or the other approach is emphasized depends on the task characteristics and the learner portfolio, described in component $\mathrm{C}$. This subsection describes both approaches as well as their combination.

First, system-controlled instruction has become much easier to realize with the upsurge of computer-assisted instruction, because it is no longer the teacher who has to make 
decisions for each individual learner. System-controlled approaches to task selection aim at selecting just-in-time the most suitable learning task from an existing database with tasks, on the basis of information representing what the learner is already able to do or not yet able to do, and/or what the learner already knows or does not yet know. Intelligent Tutoring Systems (ITS), which are adaptive problem-solving environments, have been recognized by artificial intelligence researchers as rich environments that capture some benefits of human tutors. In a typical ITS, a distinction is made between a domain model representing the domain that must be learned, a student model representing what the learner is already able to do or not yet able to do as an "overlay" of the domain model, and an instructional agent which makes decisions on the selection of learning tasks, feedback, presentation modes, and so forth (Corbett, Koedinger, \& Hadley, 2001). Originally, ITSs focused on part-task approaches teaching the domain piece by piece. Only with the introduction of dynamic whole-task approaches to teaching over the last decade, it became possible to apply techniques for task selection to learning environments for complex cognitive skills (for a review, see Salden, Paas, \& van Merriënboer, in press).

An example of an electronic learning environment that allows for personalization is the Completion Assignment Constructor (CASCO) described by van Merriënboer and Luursema (1996). It is an ITS for teaching introductory computer programming. CASCO's decisions are based on a student model and made by an instructional agent using rules for the construction and selection of learning tasks. Fuzzy-logic rules are used to construct completion tasks from worked-out examples (ranging from tasks for which the student must add a few lines to a computer program, to tasks for which the student must write nearly the whole program) and to prioritize those learning tasks from 'most suitable' to 'least suitable' for presentation to an individual learner. Van Merriënboer et al., (2002) conducted a study with CASCO in which learners received tasks with no support, support, and personalized 
support. For a transfer test that was performed after the learning tasks, the proportion of correctly used programming concepts was higher for the personalized support group than for the no-support and support groups.

Other studies have found positive results of personalizing the level of difficulty of learning tasks on the basis of performance and mental effort scores (combined in a measure of expertise). In the domain of Air Traffic Control, Camp et al., (2001) and Salden et al., (2004) compared the effectiveness of a fixed easy-to-difficult sequence of learning tasks with dynamic task selection aiming at personalized difficulty: The higher the level of expertise of the learner, the more difficult the next learning task. In both studies, personalized task difficulty yielded more efficient transfer test performance than the use of a fixed sequence of easy-to-difficult tasks. Finally, Kalyuga and Sweller (2005) conducted a study in the domain of algebra in which both the level of difficulty and the given support for the next task were adapted to learner expertise. In their study, learners in the group with personalized support and difficulty showed higher gains in algebraic skills from pretest to posttest and higher gains in cognitive efficiency than learners in a yoked control group.

Second, besides system-controlled approaches to task selection, there is an increasing tendency to make education student-centered. Learner-controlled instruction assumes that learners are able to monitor their own learning and that this will accommodate individual differences. From a student-centered perspective, personalization seeks to take into account the special needs of individual learners (Brna \& Cox, 1998). Furthermore, technological advances make it possible to implement types of computer-assisted instruction such as simulations and microworlds, which provide a lot of freedom to learners. These applications allow learners to control diverse aspects of the presented learning tasks (Bell \& Kozlowski, 2002). 
The provision of learner control has an evident influence on learner's performance (Gray, 1987; Kinzie, Sullivan, \& Berdel, 1988), since success in performance depends, amongst other factors, on the learner's level of expertise in the domain and on the learner's self-regulation skills to make proper use of the control provided and select appropriate aspects of the learning tasks. Novices in a domain or students with poor self-regulation skills lack the ability to make productive use of learner control. They may not select the necessary aspects of learning tasks because they lack adequate knowledge to make educational decisions relevant for learning. Niemiec, Sikorski, and Walberg (1996) conclude that as the level of expertise increases, it is appropriate to decrease system control and increase learner control. In an old study carried out by Fry (1972), low-expertise learners learned significantly less than highexpertise learners in a learner-controlled condition. Gay (1986) also found that in a learnercontrolled condition, learners with low prior understanding achieved significantly lower posttest results than learners with high prior understanding.

Personalizing the level of learner control according to the level of expertise of the learner might help learners to practice their self-regulation skills and further develop those skills. According to Merrill (1994), by providing control, learners are brought in a position to "learn better how to learn". Thus, gradually increasing the level of learner control might promote self-regulation skills, that is, the learners' ability to properly select learning tasks according to their abilities, interest and needs. In addition, both actual learner control and even perceived control may positively influence learner motivation. A study carried out by Lahey, Hurlocj, and McCann (1973) shows that the perception of learner control has a favorable influence on learners' attitudes. Fry's research (1972) concluded that learners with higher degrees of learner control learned the least but had the most favorable attitudes toward the method of instruction. In a study carried out by Kinzie and Sullivan (1989), 79\% of the students in the learner-controlled condition chose to return to the same condition rather than 
to a system-controlled condition. In contrast, only $19 \%$ of the students in the systemcontrolled condition chose to return to the system-controlled condition. Lahey et al., (1973) also found that learners preferred learner-controlled instruction over system-controlled instruction, although no differences in performance were found. Thus, giving control to learners not always leads to a higher performance but evidently affects motivation in a positive way (Judd, 1972; Lahey, 1976).

Third, a personalized task-selection model with shared instructional control combines system-controlled and learner-controlled approaches to the selection of learning tasks. It aims to cope with the emerging need to personalize authentic and complex learning tasks to each individual learner, preventing cognitive overload by dynamically adapting the level of task difficulty and embedded support. According to our model, an instructional agent first personalizes the characteristics (i.e., difficulty, support, other features) of the presented learning tasks based on learner's expertise (as in Camp et al., 2001; Kalyuga \& Sweller, 2005; Salden et al., in press), and second encourages learners to make a final selection from the subset of tasks preselected by the instructional agent. Thus, possible negative effects of too much learner control are reduced by limiting the amount of tasks to choose from, which will still give learners a sense of control without overwhelming them and hampering learning (Kinzie \& Sullivan, 1989).

The extent to which either the system or the learner have control over task characteristics (i.e., level of task difficult, embedded support, and task features) mainly depends on the level of expertise of the learner. In other words, personalization (component $\mathrm{P}$ ) is strongly influenced by the task characteristics and the learner portfolio (component C). On the continuum from system-controlled instruction to learner-controlled instruction, novices who lack the necessary level of knowledge to select optimal learning tasks are placed on the system-controlled side, while more experienced learners are placed on the learner- 
controlled side. So, as the level of expertise increases, system control will decrease and learner control will increase. However, even highly experienced learners should not always be given full learner control. If the amount of tasks in the learning-task database is very large (e.g., hundreds of tasks), even expert learners may become overwhelmed and demotivated by an excessive amount of freedom (Schwartz, 2004). The learning-task database (component L) is further explained in the next section.

\section{Component L: Learning tasks}

Learning tasks differ from each other with regard to difficulty, embedded support and — sometimes many — other task features, making it necessary to develop an extensive range of tasks that include and combine those characteristics. The tasks are stored in a learning-task database, which contains tasks with all possible combinations of levels of support and complexity as well as enough variability over other task features to allow for generalization and abstraction by the learner. Learning tasks that are suitable for presentation according to the instructional agent are selected in real-time from this database. Table 1 shows an example of how task complexity, embedded support, and task features might be interrelated to each other in the learning-task database.

Table 1 Table 1 shows three levels of increasing complexity or difficulty (from top to bottom). Within each of the three complexity levels, tasks represent five decreasing levels of learner support (i.e., from worked-out examples to conventional tasks). The faster the increase of expertise of the learner, the faster he or she advances to higher complexity levels, and the lower the support he or she will receive in the next learning task. In addition, for each specific complexity and support level, different tasks are available with different task features (in Table 1, for instance, there are three tasks for each combination of difficulty and support). After a subset of tasks has been pre-selected from the learning-task database, the learner makes a final selection of one task to work on. 


\section{The model into practice}

This section presents an application developed according to our model (see Figure 2).

Figure 2 An electronic learning environment has been developed enabling learners to work on learning tasks in the domain of dietetics. Learning tasks differ in their level of complexity, level of support, and other task features (as described in Component C). The learning environment is a Web application written in the scripting language PHP. Learning tasks are presented in the learning environment, and after each learning task multiple-choice questions and a mental effort rating scale are presented to measure performance and mental effort and to calculate an expertise score. A MySQL database connected to the learning environment contains all learning tasks, multiple-choice questions, a personalization table, and various kinds of logging information.

A simulator called Body-Weight ${ }^{1}$ is used by the learners to perform all necessary operations needed to answer the multiple-choice questions presented during the learning tasks. Its main purpose is to help learners understand how body weight is influenced by food intake, physical activity, and several other factors. In the simulator, the students can practice the learning tasks presented in the electronic learning environment; it is the interface that confronts them with authentic real-life situations. The learning tasks, in combination with the simulator, allow learners to study the effects on body weight and body composition (e.g., total fat percentage) of alterations in energy intake, physical activity, and other factors such as gender and smoking.

The application contains a learning-task database (Component L) with tasks that are representative for the domain of dietetics. The task characteristics as described by Component $\mathrm{C}$, that is, level of complexity, embedded support, and other task features are combined in this database. Five levels of complexity are distinguished in a simple-to-complex order. Within each complexity level, five levels of embedded support are differentiated. Moreover, for each 
level of support within each complexity level, three tasks are available with differing task features that also vary in the real world: Different persons with different gender, weight, age, energy intake, specific diet, physical exercise, cultural backgrounds, different habits, and so forth.

An assessment tool assesses performance and invested mental effort after each learning task to update the learner portfolio (Component $\mathrm{C}$ ) and to provide the information for the selection of the next learning task. In order to assess performance, learners must answer multiple-choice questions, based on predefined performance objectives, after each task. Moreover, the assessment tool monitors learner's actions on the simulator in order to assess the accuracy of the problem-solving process. Such measures make possible the assessment of the learner's performance in real-time after each task is performed, an important requisite for a system that dynamically adapts learning tasks. The results of both the multiple-choice questions and the accuracy of the process are combined in one measure of performance. A 7point subjective rating scale is used to assess the learner's investment of mental effort in the learning task, with values ranging from extremely low (1) to extremely high (7). The scale is adapted from the original mental effort scale developed by Paas (1993). Performance and mental effort scores are updated in the learner portfolio after each learning task.

The learner portfolio contains the information collected by the assessment tool. The portfolio enables the selection of a subset of suitable learning tasks from which the learner can make a final selection. It is updated after each learning task by combining new performance and invested mental effort scores with previous scores (i.e., the learner's history). It is important to take the learning history into account because this flattens out undesirable effects due to unstable measures, for instance, a high performance measure that is not due to acquired knowledge and skills but to good luck. The new scores in the learner portfolio are used by the 
instructional agent to personalize the selection of the next learning task(s) in such a way that is best suits the individual learner at a particular moment in time.

Finally, the personalization (Component $\mathrm{P}$ ) that is realized by the instructional agent is twofold: (a) the updated learner portfolio is used to select a subset of suitable learning tasks from the learning-task database, and (b) the selected tasks are presented to the learner who makes the final selection. The system employs a simple task-selection algorithm that decides on the "jump size" from one complexity level to another complexity level, and from one level of support to another level of support, on the basis of a combination of performance and mental effort scores. The algorithm is presented in Table 2. performance and mental effort scores. Basically, mental effort scores (ME) are subtracted from performance (P) scores to compute the jump size. Thus, the higher the performance and the lower the invested mental effort, the larger the positive jump size. For instance, a score of 5 on performance and 2 on mental effort yields a jump size of $+3(5-2=3)$, meaning that the level of support decreases 3 levels, or, if there are less than three support levels available at the current complexity level, the learner will move to the lowest support level because the learner is only allowed to progress to a next complexity level after successful completion of a conventional, non-supported task. Accordingly, the lower the performance and the higher the invested mental effort, the larger the negative jump size. For instance, a score of 2 on performance and 5 on mental effort yields a backward jump of 3 steps $(2-5=-3)$, meaning that either the level of support increases 3 levels, or, if there are less than three support levels available at the current complexity level, the learner will move back to the highest level of support at the current complexity level. The algorithm applies some additional rules to make the instruction encouraging and motivating for the learners. If the performance score is 5 or higher or the mental effort score is 2 or lower, the learner will not jump backwards. And if the 
performance score is 3 or lower or the mental effort score is 6 or higher, the learner will not jump forward.

\section{Discussion and conclusions}

This article discussed a personalized task-selection model with shared instructional control, combining system-controlled and learner-controlled approaches to the selection of learning tasks. It has been found that personalization of learning tasks yields more efficient and more effective learning than a fixed sequence of learning tasks that is identical for all learners. In addition, learner control is believed to make learning more appealing and to encourage the development of learners' self-regulation skills. The proposed model combines the strong points of both approaches and was therefore expected to make learning more effective (i.e., higher transfer test performance), more efficient (i.e., a more favorable ratio between performance and time on task or mental effort), and more appealing (i.e., the learner will show more interest in the learning tasks). A higher motivation will also positively influence the amount of mental effort learners invest in learning and their willingness to become engaged in additional instructional activities. If learners attribute 'better outcomes' to the 'investment of more mental effort' they will perceive a higher self-efficacy while implementing the required actions to perform such tasks, which in turn will positively affect motivation (Bandura, 1997; Keller, 1983; Kinzie, Sullivan, \& Berdel, 1988).

A pilot study has been conducted in order to examine whether personalized selection of learning tasks with shared instructional control led to better results than personalized instruction with full system control. Twenty-five nursing students (6 males and 19 females) from a school for senior vocational education in Eindhoven (the Netherlands) participated in this pilot study. Their average age was 18.2 years $(S D=3.66)$. Twelve and thirteen learners were randomly allocated to the system-controlled condition and the shared-controlled condition, respectively. Results on both performance scores and invested mental effort were 
in the expected direction (see Table 3). Participants in the shared-controlled condition achieved a higher mean performance score (i.e., Cohen's $d=0.25$ which indicates a small effect size) and a lower mean mental effort score $(d=0.37$ which indicates a small effect size) than participants in the system-controlled condition. Instructional efficiency (see Paas \& van Merriënboer, 1993; Paas et al., 2003) was computed on the basis of performance and invested mental effort. When the performance is higher than might be expected on the basis of invested mental effort $(\mathrm{P}>\mathrm{ME})$ the instruction is relatively efficient, and when the performance is lower than might be expected on the basis of invested mental effort $(\mathrm{P}<\mathrm{ME})$ the instruction is relatively inefficient. Results on instructional efficiency are in the expected direction, with a higher mean efficiency score for the shared-controlled condition $(d=0.36$ which indicates a small effect size; see Table 3).

Table 3 Motivation was measured with items from the interest/enjoyment subscale of the Intrinsic Motivation Inventory (IMI; Deci, Eghrari, Patrick, \& Leone, 1994), which were translated into Dutch by Martens and Kirschner (2004). On a questionnaire with 7-point scales filled out after the course, learners in the shared instructional control condition reported a slightly significant higher interest in the learning tasks than learners in the full systemcontrol condition $(p<.10 ; d=0.79$ which indicates a medium effect size; see Table 3$)$.

The results of the pilot study provide some preliminary evidence that the personalized model is a promising approach to increase the flexibility and quality of educational programs. Moreover, they support the idea that the provision of (limited) learner control may enhance learners' motivation. In a follow-up study, non-personalized conditions will be included and the variability of task features will be drastically increased, so that the learners can choose from many more tasks differing from each other on various features (note that in the current pilot study learners could only choose from three quite similar tasks). 
Some final comments have to be made. With regard to the assessment of complex performance, the PPS requires the measurement of many qualitatively different aspects with different measurement instruments. Our application only employed multiple-choice questions and accuracy scores to assess performance, and a rating scale to assess the mental effort invested to reach this performance. Future studies need to assess qualitatively different aspects (e.g., problem-solving aspects, routine aspects, attitudinal aspects) and use different measurement instruments to develop a learner portfolio with valid and reliable information to base the selection of learning tasks on.

With regard to the level of learner control, future studies may progressively increase learner control as the level of learners' expertise increases. For instance, first giving novices only control over selecting task features with a given support and complexity (as in the presented pilot study), then giving them, as expertise increases, control over task features and the amount of learner support, and finally giving them control over task features, support, as well as task complexity. This way, the complex relationships between task features, support, and complexity are considered together with the level of expertise. If too much control is given to novices in the learning domain, or if too little control is given to experienced learners, this may hamper their learning, performance and motivation. However, the question still remains how to combine learner and task characteristics most effectively, and therefore how to balance system and learner control (component P in Figure 1) for each learner. Giving novices full system control may demotivate them, and giving experienced learners full learner control may overwhelm them if the amount of tasks to choose from is very large. As Schwartz (2004) argues, “... at this point, choice no longer liberates, but debilitates” (p. 2).

Another relevant issue is raised by Bell and Kozlowski (2002), who found in their study positive effects on the nature of the learners' study and practice, self-regulation, knowledge acquired, and performance when students with learner control received some form 
of advice. Specifically, meta-cognitive advisory models explicitly help students to apply cognitive strategies for assessing their own performance, and to select new learning tasks based on this assessment, which may enhance their cognitive strategies for regulating their own learning. Recently, a study has been initiated to test this assumption (Kicken, BrandGruwel, \& van Merriënboer, 2005). Thus, future studies may integrate shared instructional control with advisory models that help learners to select appropriate tasks.

To conclude, the first results of an application built according to our personalized model with shared instructional control are promising. However, this is only a first step towards more flexible, demand-driven educational programs. Future studies also need to personalize the amount of learner control to the learner's level of expertise, and include advisory models to assist learners with their decisions until they eventually become selfregulated high-ability learners. 


\section{Acknowledgements}

This research project is funded by the Netherlands Organization for Scientific Research (NWO, The Hague, project no. 411-02-107-V). The authors gratefully acknowledge the assistance of Irma Rabelink (ROC Eindhoven) before and during carrying out of the pilot study. 


\section{Endnotes}

${ }^{1}$ The Body Weight simulator was developed based on the calculation model from Dr. K. Westerterp, Rijksuniversiteit Limburg, the Netherlands.

\section{References}

Bandura, A. (1997). Self-efficacy: The exercise of control. New York: W. H. Freeman.

Bell, B. S., \& Kozlowski, S. W. J. (2002). Adaptive guidance: Enhancing self-regulation, knowledge, and performance in technology-based training. Personnel Psychology, 55: 267-306.

Brna, P., \& Cox, R. (1998). Adding intelligence to a learning environment: Learner-centred design? Journal of Computed Assisted Learning, 14: 268-277.

Camp, G., Paas, F. G. W. C., Rikers, R., \& van Merriënboer, J. (2001). Dynamic problem selection in air traffic control training: A comparison between performance, mental effort and mental efficiency. Computers in Human Behavior, 17: 575-595.

Corbett, A. T., Koedinger, K. R., \& Hadley, W. H. (2001). Cognitive Tutors: From the research classroom to all classrooms. In P. S. Goodman, eds, Technology Enhanced Learning: Opportunities for Change, pp. 235-263. Mahwah, NJ: Lawrence Erlbaum Associates.

Deci, E. L., Eghrari, H., Patrick, B. C., \& Leone, D. (1994). Facilitating internalization: The self-determination theory perspective. Journal of Personality, 62: 119-142.

Fry, J. P. (1972). Interactive relationship between inquisitiveness and learner control of instruction. Journal of Educational Psychology, 63: 459-465.

Gay, G. (1986). Interaction of learner control and prior understanding in computer-assisted video instruction. Journal of Educational Psychology, 78: 225-227.

Gray, S. J. (1987). The effects of sequence control on computer learning. Journal of Computer-based Instruction. 14(2): 54-56. 
Judd, W. A. (1972). Learner-controlled computer-assisted instruction. ERIC \#ED 072-635.

Kalyuga, S., Ayres, P., Chandler, P., \& Sweller, J. (2003). The expertise reversal effect. Educational Psychologist, 38(1): 23-31.

Kalyuga, S., \& Sweller, J. (2005). Rapid dynamic assessment of expertise to optimize the efficiency of e-learning. Educational Technology, Research and Development, 53(3).

Keller, J.M. (1983). Motivational design of instruction. In C.M. Reigeluth, eds, InstructionalDesign Theories and Models: An Overview of their Current Status, pp. 383-434, Hillsdale, NJ: Erlbaum.

Kicken, W., Brand-Gruwel, S., \& van Merriënboer, J. J. G. (2005, May-June). Advisering bij het kiezen van leertaken: Veilig op weg naar vraaggestuurd onderwijs [Advice on the selection of learning tasks: A safe approach to education on-demand]. Paper presented at the OnderwijsResearchDagen (ORD), May 30-June 1, Gent, Belgium.

Kinzie, M. B. (1990). Requirements and benefits of effective interactive instruction: Learner control, self-regulation, and continuing motivation. Educational Technology, Research \& Development, 38(1): 5-21.

Kinzie, M. B., \& Sullivan, H. J. (1989). Continuing motivation, learner control, and CAI. Educational technology, Research, and Development, 37(2): 5-14.

Kinzie, M. B., Sullivan, H.J., \& Berdel, R. L. (1988). Learner control and achievement in science computer-assisted instruction. Journal of Educational Psychology, 80: 299303.

Lahey, G. F. (1976). Leaner-control of lesson strategy: A model for PLATO IV system lessons. ERIC \#ED 125-543.

Lahey, G. F., Hurlock, R. E., \& McCann, P. H. (1973). Post-lesson remediation and student control of branching in computer-based learning. ERIC \#ED 083-797. 
Lawless, K.A., \& Brown, S.W. (1997). Multimedia learning environments: Issues of learner control and navigation. Instructional Science, 25: 117-131.

Martens, R. L. \& Kirschner, P. A., (2004). What predicts intrinsic motivation? Paper presented at the 2004 AECT convention, Chicago.

Merrill, M. D. (1994) Instructional Design Theory. Englewood Cliffs, NJ: Educational Technology Publications.

Merrill, M. D. (2002). Instructional strategies and learning styles: Which takes precedence?. In R.A. Reiser, \& J.V. Dempsey, eds, Trends and Issues in Instructional Technology. Upper Saddle River, NJ: Merrill Prentice Hall.

Niemiec, P., Sikorski, C., \& Walberg, H. (1996). Learner-control effects: A review of reviews and a meta-analysis. Journal of Educational Computing Research, 15(2): 157-174.

Paas, F. G. W. C. (1993). Instructional control of cognitive load in the training of complex cognitive tasks. Doctoral dissertation, University of Twente, Enschede, The Netherlands.

Paas, F. G. W. C., Tuovinen, J. E., Tabbers, H., \& van Gerven, P. (2003). Cognitive load measurement as a means to advance cognitive load theory. Educational Psychologist, 38: 63-71.

Paas, F. G. W. C., Tuovinen, J., Van Merriënboer, J. J. G., \& Darabi, A. (in press). A motivational perspective on the relation between mental effort and performance: Optimizing learner involvement in instruction. Educational Technology, Research \& Development.

Reigeluth, C. (1999) (Ed.). Instructional Design Theories and Models: A New Paradigm of Instructional Theory (Vol. II). Mahwah, NJ: Lawrence Erlbaum. 
Renkl, A., \& Atkinson, R. K. (2003). Structuring the transition from example study to problem solving cognitive skill acquisition: A cognitive load perspective. Educational Psychologist, 38: 15-22.

Salden, R.J.C.M., Paas, F. G. W. C., \& van Merriënboer, J.J.G. (in press). A comparison of approaches to learning task selection in the training of complex cognitive skills. Computers in Human Behavior.

Salden, R.J.C.M., Paas, F. G. W. C., Broers, N.J., \& van Merriënboer, J.J.G. (2004). Mental effort and performance as determinants for the dynamic selection of learning tasks in air traffic control training. Instructional science, 32: 153-172.

Schwartz, B. (2004). The Paradox of Choice: Why More is Less. New York: Ecco.

Shute, V., \& Towle, B. (2003). Adaptive e-learning. Educational Psychologist, 38(2): 105-114. Straetmans, G., Sluijsmans, D., Bolhuis, B., \& van Merriënboer, J. J. G. (2003). Integratie van instructie en assessment in competentiegericht onderwijs [Integration of instruction and assessment in competence based education]. Tijdschrift voor Hoger Onderwijs, 3: 171197.

Sweller, J. (1988). Cognitive load during problem solving: Effects on learning. Cognitive Science, 12: 257-285.

Sweller, J. (1994). Cognitive theory; learning difficulty, and instructional design. Learning and Instruction, 4: 295-312.

Sweller, J., van Merriënboer, J. J. G., \& Paas, F. G. W. C. (1998). Cognitive architecture and instructional design. Educational Psychology Review, 10: 251-296.

Van Merriënboer, J. J. G. (1997). Training Complex Cognitive Skills. Englewood Cliffs: Educational Technology Publications.

Van Merriënboer, J., Clark, R., \& de Croock, M. (2002). Blueprints for complex learning: The 4C/ID-model. Educational Technology, Research and Development, 50: 39-64. 
Van Merriënboer, J. J.G., \& Kirschner, P (2001). Three worlds of instructional design: State of the art and future directions. Instructional Science, 29: 429-441.

Van Merriënboer, J. J. G., Kirschner, P.A., \& Kester. L. (2003). Taking the load off a learner's mind: Instructional design for complex learning. Educational Psychologist, 38: 5-13.

Van Merriënboer, J., \& Luursema, J. (1996). Implementing instructional models in computerbased learning environments: A case study in problem selection. In T. Liao (Ed.), Advanced Educational Technology: Research Issues and Future Potential, pp. 184206, Berlin: Springer Verlag.

Van Merriënboer, J. J. G., Schuurman, J., de Croock, M., \& Paas, F. G. W. C. (2002). Redirecting learner's attention during training: Effects on cognitive load, transfer test performance and training efficiency. Learning and Instruction, 12: 11-37.

Van Merriënboer, J. J. G., \& Sweller, J. (2005). Cognitive load theory and complex learning: Recent developments and future directions. Educational Psychology Review, 17(2): 147-177.

Wolters, C. A. (2003). Regulation of motivation: Evaluating an underemphasized aspect of self-regulated learning. Educational Psychologist, 38(4): 189-205.

Zimmerman, B. J. (2002). Achieving academic excellence: A self-regulatory perspective. In M. Ferrari (Ed.), The Pursuit of Excellence Through Education, pp. 85-110. Mahwah, NJ: Erlbaum 
Table 1

Learning-task database with the combination of different levels of complexity and different levels of support

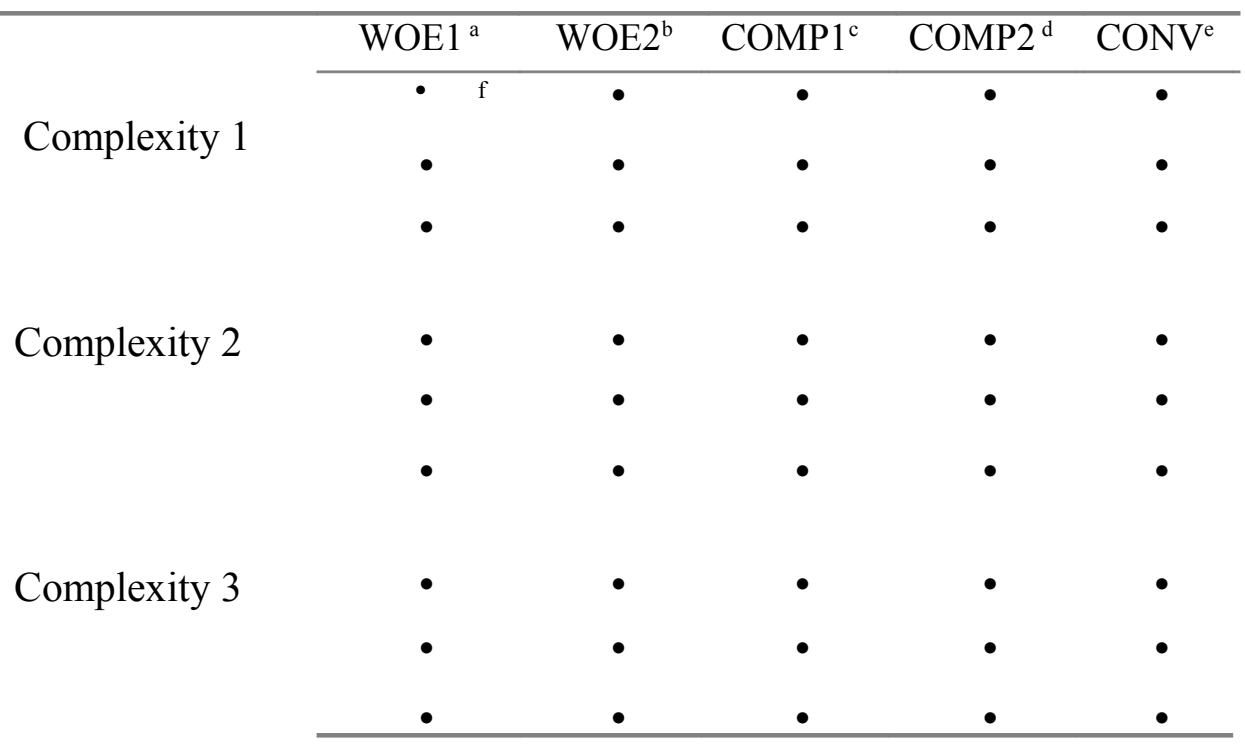

${ }^{\text {a }}$ WOE $1=$ Worked-out example with process and full product support

${ }^{\mathrm{b}}$ WOE2 $=$ Worked-out example with full product support

${ }^{\mathrm{c}} \mathrm{COMP} 1=$ Completion task with high product support

${ }^{\mathrm{d}} \mathrm{COMP} 2=$ Completion task with low product support

${ }^{\mathrm{e}} \mathrm{CONV}=$ Conventional task without support

${ }^{\mathrm{f}}=$ Learning task. Each cell contains several ( 3 in the table) learning tasks with different task features that belong to one complexity level and one level of learner support

Table 2

Task-selection algorithm indicating jump sizes between learning tasks 


\begin{tabular}{|c|c|c|c|c|c|c|c|}
\hline \multirow{2}{*}{$\begin{array}{l}\text { Mental } \\
\text { effort }\end{array}$} & \multicolumn{7}{|c|}{ Performance } \\
\hline & 1 & 2 & 3 & 4 & 5 & 6 & 7 \\
\hline 1 & 0 & 0 & 0 & +3 & +4 & +5 & +6 \\
\hline 2 & 0 & 0 & 0 & +2 & +3 & +4 & +5 \\
\hline 3 & -2 & -1 & 0 & +1 & +2 & +3 & +4 \\
\hline 4 & -3 & -2 & -1 & 0 & +1 & +2 & +3 \\
\hline 5 & -4 & -3 & -2 & -1 & 0 & +1 & +2 \\
\hline 6 & -5 & -4 & -3 & -2 & 0 & 0 & 0 \\
\hline 7 & -6 & -5 & -4 & -3 & 0 & 0 & 0 \\
\hline
\end{tabular}


Table 3

Overview of test results and interest

Method of personalized training

Shared instructional control

$M$

Mental effort

Performance

Mental Efficiency

Interest in training *
$S D$

1.08

13.70

1.12

0.95
59.43

2.77

Full system control

$M \quad S D$

4.11

55.52

$-0.23$

1.15

2.05

17.87

1.34

0.88

$p<.10$

Figure Captions

Figure 1. The personalized model for dynamic task selection. 
Figure 2. Learning environment developed on the basis of the personalized model. The basic components are: (a) an electronic learning environment, (b) a learning-task database, (c) an assessment tool, (d) a learner portfolio, and (e) an instructional agent to realize personalization.

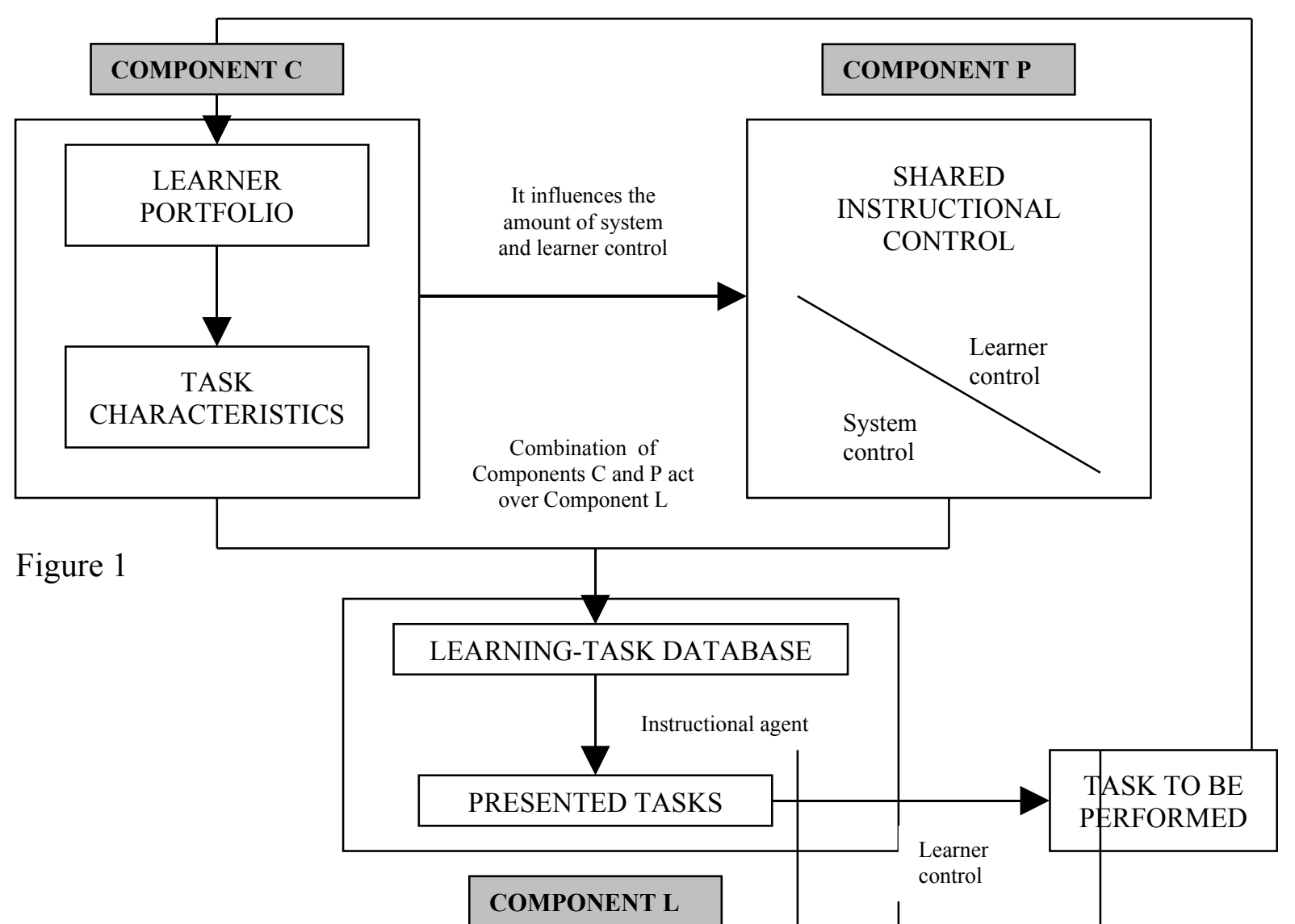


Shared control over task selection 36 
Figure 2

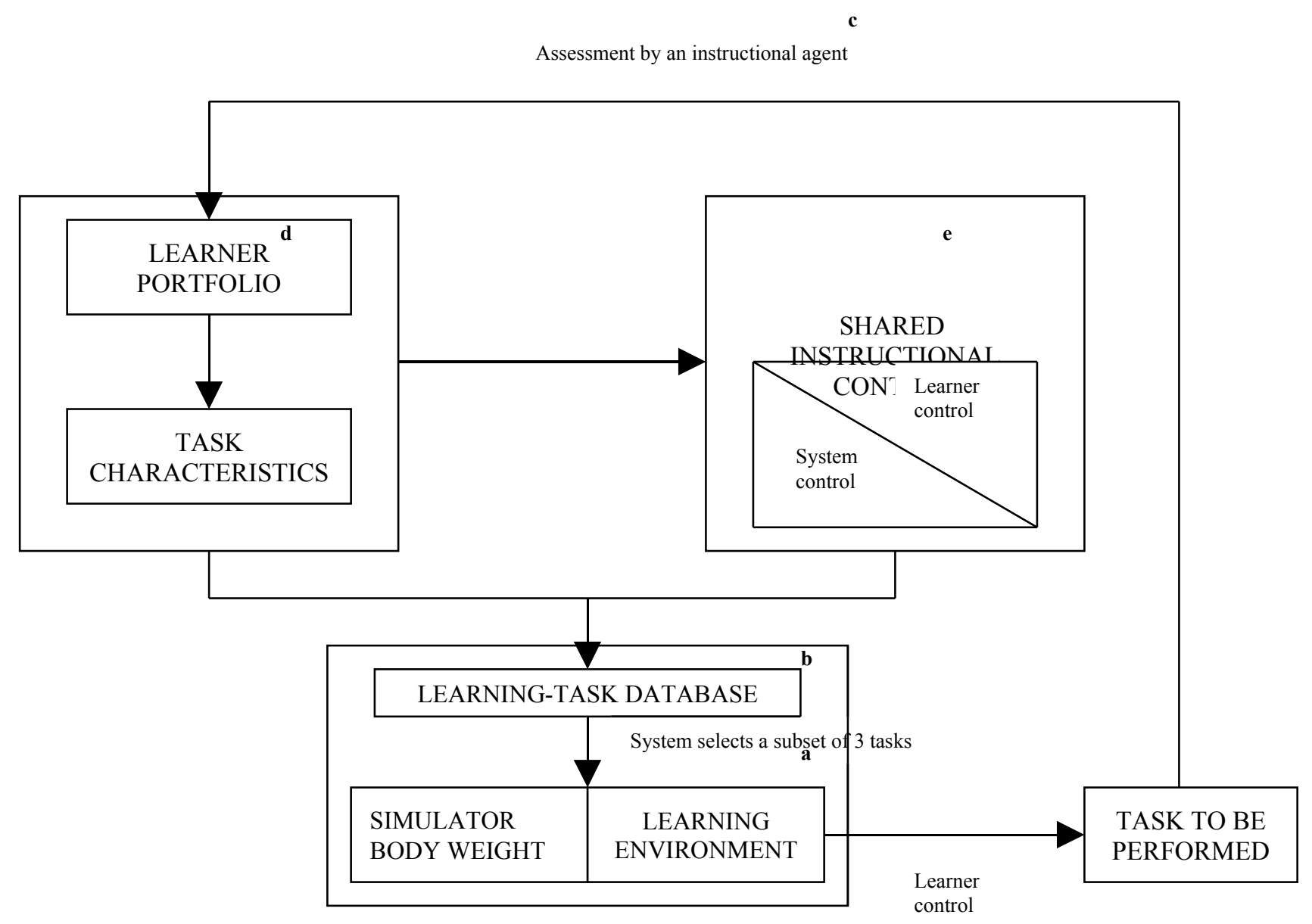

